\section{Zentrale Schlafapnoe unter Therapie}

Helga Peter

Marburg, Deutschland

\section{Synonyme}

Komplexe Schlafapnoe

\section{Englischer Begriff}

treatment-emergent central sleep apnea; complex sleep apnea

\section{Definition}

Der Begriff bezeichnet das Auftreten oder Persistieren von zentralen Apnoen unter der Atemwegsdrucktherapie einer Obstruktiven Schlafapnoe und wurde als Diagnose neu in die ICSD-3 (2014) aufgenommen. Damit wurde der wissenschaftlichen Diskussion und der praktischen Bedeutung des Phänomens Rechnung getragen. Der vorher gebräuchliche Begriff komplexe Schlafapnoe war nicht eindeutig definiert und wurde häufig nicht einheitlich verwendet.

Siehe auch $\triangleright$,Zentrale Schlafapnoesyndrome“. 